\title{
Energy intake from human milk covers the requirement of 6-month-old Senegalese exclusively breast-fed infants
}

\author{
Anta Agne-Djigo, Komlan M. Kwadjode, Nicole Idohou-Dossou, Adama Diouf, \\ Amadou T. Guiro and Salimata Wade* \\ Laboratoire de Nutrition, Département de Biologie Animale, Faculté des Sciences et Techniques, \\ Université Cheikh Anta Diop de Dakar, BP 5005, Fann-Dakar, Senegal
}

(Submitted 7 September 2012 - Final revision received 5 March 2013 - Accepted 5 March 2013 - First published online 12 April 2013)

\section{Abstract}

Exclusive breast-feeding until 6 months is advised by the WHO as the best practice to feed infants. Yet, some studies have suggested a gap between energy requirements and the energy provided by human milk for many infants at 6 months. In order to assess the adequacy of WHO recommendations in 6-month-old Senegalese lactating infants, a comprehensive study was designed to measure human milk intake by the dose-to-the mother ${ }^{2} \mathrm{H}_{2} \mathrm{O}$ turnover method. Infants' energy intakes were calculated using daily breast milk intake and the energy content of milk was estimated on the basis of creamatocrit. Of the fifty-nine mother-infant pairs enrolled, fifteen infants were exclusively breast-fed (Ex) while forty-four were partially breast-fed (Part). Infants' breast milk intake was significantly higher in the Ex group (993 (sD 135) g/d, $n$ 15) compared with the Part group (828 (sD 222) g/d, $n$ 44, $P=0.009$ ). Breast milk energy content as well as infants' growth was comparable in both groups. However, infants' energy intake from human milk was significantly higher (364 (sD 50$) \mathrm{kJ} / \mathrm{kg}$ per $\mathrm{d}(2586(\mathrm{sD} 448) \mathrm{kJ} / \mathrm{d})$ ) in the Ex group than in the Part group (289 (sD 66) kJ/kg per d (2150 (sD 552) kJ/d), P<0.01). Compared with WHO recommendations, the results demonstrate that energy intake from breast milk was low in partially breast-fed infants while exclusively breast-fed 6-month-old Senegalese infants received adequate energy from human milk alone, the most complete food for infants. Therefore, advocacy of exclusive breast-feeding until 6 months should be strengthened.

\section{Key words: Exclusive breast-feeding: Partial breast-feeding: Breast milk intake: Energy intake: Senegal}

Feeding patterns are major determinants of infant health. Indeed, a lack of exclusive breast-feeding during the first 6 months of life is an important risk factor for infant and childhood morbidity and mortality, especially in developing countries $^{(1)}$. Exclusive breast-feeding means that no water or other fluids or food is given to the infant in addition to breast milk. Partial breast-feeding means the infant receives foods or other milk ${ }^{(2,3)}$ in addition to breast milk. Based on the findings of Da Costa et al. ${ }^{(4)}$, breast-feeding is considered exclusive when non-milk intake is less than $100 \mathrm{~g} / \mathrm{d}$, and partial when it is over $100 \mathrm{~g} / \mathrm{d}$.

There is a long debate over the adequacy of exclusive breast-feeding until 6 months of age in developing countries. This debate is centred on the 'weanling's dilemma', i.e. the choice between the known protective effect of exclusive breast-feeding against infectious morbidity and the theoretical insufficiency of breast milk alone to satisfy the infant's energy and micronutrient requirements beyond 4 months of age. In addition, the most frequent reason given by mothers for solid food introduction before 6 months is that they consider the infant to be hungry and not satisfied by breast milk alone $^{(5)}$. In this regard, the WHO commissioned expert consultations and a systematic review ${ }^{(6,7)}$ to assess the scientific evidence of the optimal duration, and the nutrient adequacy of exclusive breast-feeding. Neither endeavour found any objective evidence of 'weanling's dilemma' nor any adverse effects of exclusive breast-feeding for 6 months on weight or length gain in infants. Infant growth potential drives milk production $^{(7)}$, and thus the mean intake of human milk provides sufficient energy and protein to meet requirements during the first 6 months. On this basis, exclusive breast-feeding is now recommended by the WHO as the best feeding practice for the infant up to the age of 6 months ${ }^{(1,8)}$. However, some authors still believe these grounds to be insufficient as a basis for current recommendations, and have hypothesised a gap between the energy provided by breast milk and energy needs for many 6-month-old infants in developed countries $^{(5,9,10)}$. All experts have noted a serious lack of

Abbreviations: Ex group, exclusive breast-feeding infants; Part group, partial breast-feeding infants.

*Corresponding author: A. Agne-Djigo, email antaagnedjigo@yahoo.fr 
data on breast milk composition and breast milk intake of 6-month-old infants in developing countries, and recommended more investigations with standard methods to support current recommendations. The ${ }^{2} \mathrm{H}_{2} \mathrm{O}$ tracer, the dose-to-the mother technique, is such a method to assess breast milk intake. Few studies in developing countries using this technique on 6-month-old infants have been reported; however, none of these studies has measured the adequacy of energy intake from breast milk ${ }^{(11-13)}$. Wells et al. ${ }^{(14)}$ calculated 6-month-old infants' energy consumption from breast milk based on the measurement of breast milk intake and the findings of Reilly et $a l .{ }^{(9)}$, and found that infants meet the WHO recommendations for breast milk intake but not for energy intake. The dose-to-the mother technique was first described by Coward et al. ${ }^{(15)}$ and involves giving the mother an oral dose of ${ }^{2} \mathrm{H}$-labelled water, and following the disappearance of ${ }^{2} \mathrm{H}$ from the mother and its appearance in the baby ${ }^{(16-18)}$. The major determinant of energy density in breast milk is its fat content. Therefore, an estimate of milk fat concentration can determine its energy value. The creamatocrit method has been used extensively for this estimation since it was validated for human milk by Lucas et al. ${ }^{(19)}$.

In order to assess the adequacy of WHO recommendations, the present comprehensive study was designed to estimate the energy intake from human milk in 6-month-old Senegalese lactating infants. Breast milk intake was measured by the dose-to-the-mother ${ }^{2} \mathrm{H}_{2} \mathrm{O}$ turnover method and the fat and energy contents of human milk by creamatocrit.

\section{Methods}

\section{Subjects}

Mothers of infants aged less than 6 months were identified during routine immunisation sessions at health centres in the neighbourhood of Dakar, the Senegalese capital, and were invited to participate in the study. The study was conducted according to the guidelines laid down in the Declaration of Helsinki, and all procedures involving human subjects were approved by the ethical committee of the University of Cheikh Anta Diop in Dakar. Written informed consent was obtained from all mothers

The protocol was designed as a comprehensive study, and was part of an initial evaluation powered to test the most appropriate population indicator of vitamin A deficiency in 225 mother/infant pairs. Of the mother/infant pairs from the initial sample, one-quarter were randomly selected using a computer-generated block randomisation scheme (Epi Info) for inclusion in the present study. Finally, fifty-nine breastfeeding mothers and their 6-month-old infants were included for the study. The sample size required to detect a $100 \mathrm{~g} / \mathrm{d}$ significant difference in milk intake between exclusively and partially breast-fed infants, assuming a SD of $130 \mathrm{~g} / \mathrm{d}$, a statistical power of $80 \%$ and an $\alpha$ of $5 \%$, was fifty-four mother/infant pairs.

Mothers' socio-economic status was evaluated using a questionnaire to know whether the mother was a homeowner or renting, had running water and electricity at home, to know the type of fuel used for cooking, the type of toilets used, the equipment used in the house and also whether the mother had possession of animals and/or farms for agriculture.

The recruitment was based on the fact that the infant was still breast-feeding, and was not acutely severely malnourished (a mid-upper arm circumference $\leq 11.5 \mathrm{~cm}$ and/or a weightfor-length $\leq-3 z$-score were used to define severe and acute malnutrition). Before the recruitment, mothers' Hb was screened using a HemoCue Hb 201 analyser (HemoCue AB), and those with severe anaemia $(\mathrm{Hb}<70 \mathrm{~g} / \mathrm{l})$ were excluded from the study and referred to the hospital for appropriate clinical care. Mothers with twins and pregnant women were also excluded from the study.

\section{Measurement of breast milk intake}

Infant milk intake was determined using the dose-to-the mother ${ }^{2} \mathrm{H}_{2} \mathrm{O}$ turnover method first described by Coward et $a l^{(15,20)}$ and later reported by Haisma et $a l^{(3)}$ and the International Atomic Energy Agency ${ }^{(18)}$. Briefly, baseline saliva samples of both mothers and infants were collected on day 0 (pre-dose) before an oral dose of $30 \mathrm{~g}^{2} \mathrm{H}_{2} \mathrm{O}$ (Cambridge Isotope Laboratories, Inc.) was given to the mother. The dose was weighed to the nearest $0.0001 \mathrm{~g}$ using an analytical scale (OHAUS Corporation). On days 1, 2, 3, 4, 13 and 14, six saliva samples (post-dose) were collected from both mothers and infants and the samples were stored at $-20^{\circ} \mathrm{C}$ until measurement. ${ }^{2} \mathrm{H}$ enrichment of the saliva samples was determined by a Fourier transform IR spectrometer (Nicolet iS10; Thermo Scientific). The technique is reflective of the infant's water intake from milk and non-milk water intake over $14 \mathrm{~d}^{(18)}$. Anthropometric measurements (weight and height) of both mothers and infants were recorded on the 1st and 14 th day.

\section{Calculations}

Breast milk and non-milk intakes were calculated by fitting ${ }^{2} \mathrm{H}$ enrichment data to a model of water turnover in mothers and infants using the Solver function of Microsoft Excel, as described by Coward et al. ${ }^{(15)}$ and Haisma et al. ${ }^{(3)}$.

\section{Determination of the mother's body composition}

Body composition (lean body mass and fat mass) of mothers was calculated from the total-body water component as part of the dose-to-the-mother method. Total body water was assumed to be equal to ${ }^{2} \mathrm{H}$ dilution space divided by $1.04^{(21)}$. Fat-free mass was calculated as total body water/ $0.73^{(22)}$. Body fat was computed as body weight minus fatfree mass.

\section{Determination of the infant's breast-feeding pattern}

Breast-feeding patterns were defined according to the amount of non-milk intake estimated from tracer studies. Based on the WHO definitions, exclusive breast-feeding was defined as the infant receiving only human milk without any additional food 
or drink, not even water for 6 months of life. Predominant breast-feeding consisted of breast milk as the infant's predominant source of nourishment, but the infant could also receive water and water-based drinks, fruit juice and other fluids in limited quantities. Partial breast-feeding was defined as the infant receiving foods or other milk in addition to breast milk. Haisma et al. ${ }^{(3)}$ found no difference in breast milk intake between exclusively and predominantly breastfed infants. However Haisma's classification was based on mothers' self-report, which is questionable ${ }^{(2)}$. For this reason, we chose to use actual non-milk water intake as a means to classify infants by the feeding pattern. Da Costa et $a{ }^{(4)}{ }^{(4)}$, in a multi-centre analysis of data from twelve countries using a standardised stable isotope method, have shown a decrease of $45 \mathrm{~g} / \mathrm{d}$ of human milk intake for each additional $100 \mathrm{~g} / \mathrm{d}$ of non-milk water intake. Based on this result, we considered breast-feeding to be exclusive when non-milk intake is less than $100 \mathrm{~g} / \mathrm{d}$, and partial when nonmilk intake is equal to or more than $100 \mathrm{~g} / \mathrm{d}$. Therefore, two groups were formed according to the infants' breast-feeding pattern: Ex group (exclusive breast-feeding infants) and Part group (partial breast-feeding infants)

\section{Breast milk energy content and infant's energy intake}

On day 14, a full milk sample was collected from each mother with a manual breast pump. Milk samples were collected from one breast that had not been used to feed the infant for at least $2 \mathrm{~h}$ while the infant was suckling the other one. They were well mixed and immediately after, three capillary tubes were filled for creamatocrit determination with Creamatocrit Plus ${ }^{\mathrm{TM}}$ (Separation Technology, Inc.) for creamatocrit determination. Creamatocrit has been mostly used in clinical settings and could also be used in research and epidemiological studies. In addition, it has been validated by Meier et al. ${ }^{(23)}$ against laboratory techniques for performing creamatocrit such as the standard laboratory centrifuge with a haematocrit reader and the standard laboratory centrifuge with digital calipers. Creamatocrit Plus $^{\mathrm{TM}}$ is a small centrifuge with an embedded reader system that automatically calculates the amount of fat and energy (kcal) in milk from creamatocrit values ${ }^{(19)}$.

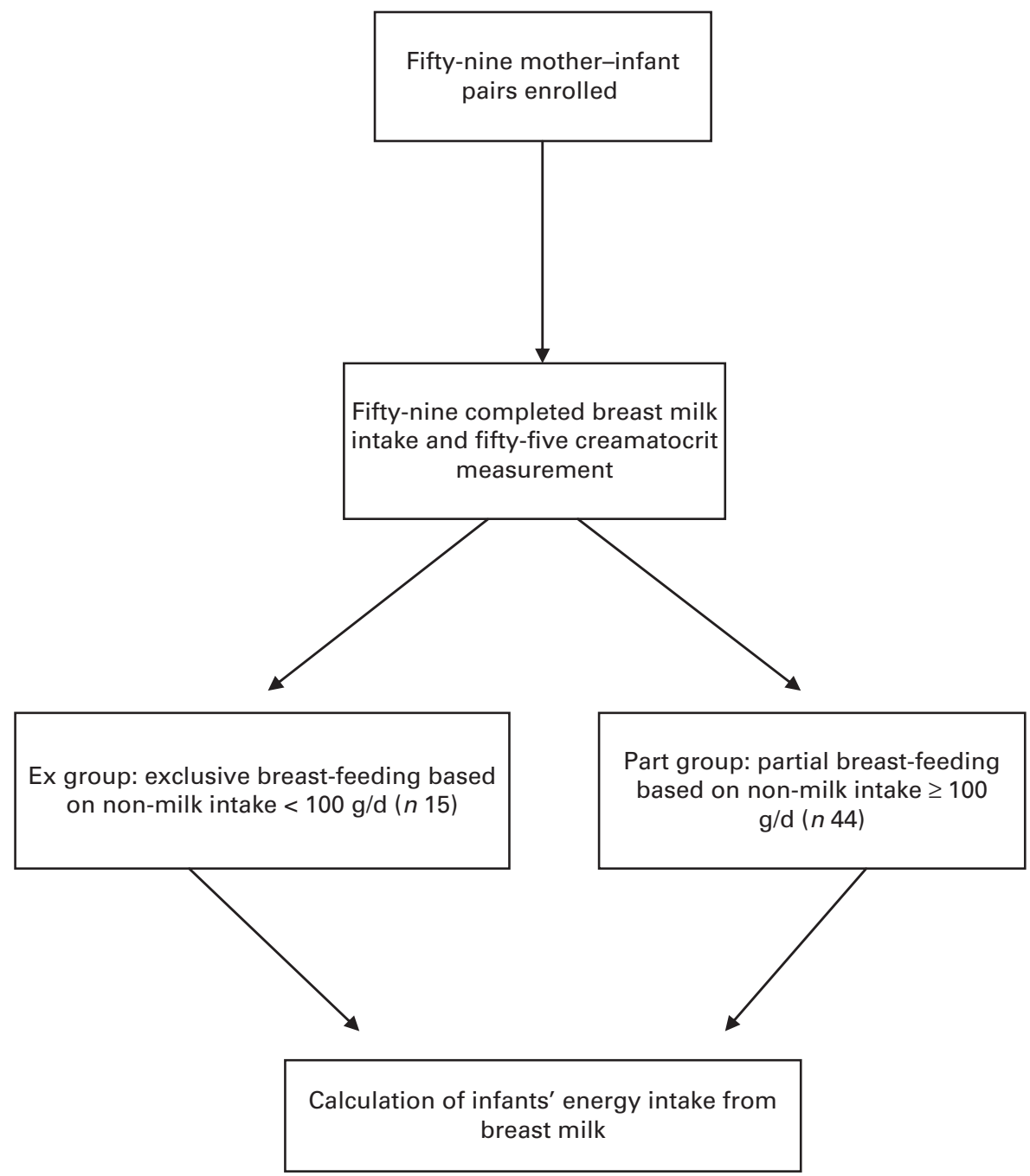

Fig. 1. Study profile. 
Table 1. Characteristics of Senegalese lactating mothers and their 6-month-old breast-feeding infants

(Mean values and standard deviations)

\begin{tabular}{|c|c|c|c|c|c|}
\hline \multirow[b]{2}{*}{ Characteristics } & \multicolumn{2}{|c|}{$\begin{array}{l}\text { Ex group } \\
(n 15)\end{array}$} & \multicolumn{2}{|c|}{$\begin{array}{l}\text { Part group } \\
\qquad(n \text { 44) }\end{array}$} & \multirow[b]{2}{*}{$P$} \\
\hline & Mean & SD & Mean & SD & \\
\hline \multicolumn{6}{|l|}{ Lactating women } \\
\hline Age (months) & 28.73 & $5 \cdot 29$ & 28.97 & $5 \cdot 67$ & $0.8 \varepsilon$ \\
\hline Weight (kg) & 64.50 & $9 \cdot 50$ & 60.52 & 10.43 & $0.1 \mathrm{~s}$ \\
\hline Height $(m)$ & 1.66 & 0.05 & 1.64 & 0.07 & 0.20 \\
\hline BMI $\left(\mathrm{kg} / \mathrm{m}^{2}\right)$ & $23 \cdot 20$ & 3.19 & $22 \cdot 41$ & 3.37 & 0.42 \\
\hline Fat-free mass $(\mathrm{kg})$ & $44.55^{\mathrm{a}}$ & 4.48 & $40 \cdot 89^{b}$ & 5.35 & 0.02 \\
\hline Fat mass $(\mathrm{kg})$ & $20 \cdot 38$ & $6 \cdot 42$ & $19 \cdot 78$ & $6 \cdot 35$ & 0.75 \\
\hline Fat percentage & 29.07 & 6.65 & $31 \cdot 26$ & 9.65 & 0.42 \\
\hline \multicolumn{6}{|l|}{ Breast-feeding infants } \\
\hline Age (months) & $5 \cdot 56$ & 0.49 & $5 \cdot 70$ & 0.44 & $0 \cdot 1$ \\
\hline Weight (kg) & $7 \cdot 13$ & 0.80 & $7 \cdot 48$ & 1.00 & 0.241 \\
\hline Length $(\mathrm{cm})$ & 66.08 & $2 \cdot 72$ & $66 \cdot 76$ & $2 \cdot 18$ & 0.33 \\
\hline WHZ (z-score) & -0.44 & 0.86 & -0.23 & 1.24 & 0.56 \\
\hline HAZ (z-score) & 0.20 & 1.17 & 0.30 & 0.98 & 0.76 \\
\hline $\begin{array}{l}\text { Weight gain } \\
(\mathrm{g} / \mathrm{kg} \text { per } \mathrm{d})^{\star}\end{array}$ & 0.96 & $2 \cdot 56$ & 1.42 & 1.32 & 0.3 \\
\hline
\end{tabular}

Ex group, exclusively breast-fed infants; Part group, partially breast-fed infants WHZ, weight-for-length; HAZ, length-for-age.

${ }^{a, b}$ Mean values within a row with unlike superscript letters were significantly different $(P<0.05)$.

* Calculated from the weight at the beginning of the study and at day 14: weight gain $=1000 \times($ weight at day 14 -weight at day 0$) /($ weight at day $0 \times 14)$.

The following equations are used by the device:

$$
\begin{aligned}
\text { Creamatocrit }= & (\text { length of the cream layer } / \text { total length of } \\
& \text { the milk column }) \times 100, \\
\text { Fat }= & 3.968+(5.917 \times \text { creamatocrit }), \\
\text { Energy }= & 385.422+(55.656 \times \text { creamatocrit }) .
\end{aligned}
$$

Infants' energy intake from breast milk was calculated as a product of breast milk intake and the energy content of the mother's milk.

\section{Statistical analysis}

Characteristics of infants and mothers are tabulated as means and standard deviations. Breast milk intake was expressed as $\mathrm{g} / \mathrm{d}$ and energy intake as $\mathrm{kJ} / \mathrm{d}$ and $\mathrm{kJ} / \mathrm{kg}$ body weight per $\mathrm{d}$. They are tabulated as means and standard deviations and 95\% CI. Statistical analysis was carried out with PASW Statistics 17 (SPSS, Inc.) and Microsoft Office Excel 2003 (Microsoft). $P$ values $<0.05$ were considered as significant. ANOVA and the $t$ test were used to compare means between the groups. Multivariate linear regressions were used to assess the association between breast milk intake and the characteristics of mothers and infants.

\section{Results}

Mothers in the study were defined as relatively poor. All the fifty-nine mother-infant pairs initially enrolled in the study completed the dose-to-the-mother ${ }^{2} \mathrm{H}$ dilution technique and fifty-five completed the creamatocrit measurements (Fig. 1).
Of the fifty-nine mother-infant pairs, fifteen infants (25.4\%) had non-milk intakes $<100 \mathrm{~g} / \mathrm{d}$ and were then considered as the Ex group, while forty-four (74.6\%) had non-milk intakes $\geq 100 \mathrm{~g} / \mathrm{d}$ and were considered as the Part group.

\section{Subjects' characteristics}

The characteristics of the fifty-nine mother-infant pairs are indicated in Table 1. Mothers' age, BMI and fat mass in the Ex group were not different from those in the Part group. However, their fat-free mass was significantly higher than that of the Part group mothers $(P=0 \cdot 021)$. Of the fifty-nine subjects, $7 \%(n 4)$ of mothers had energy deficiency (BMI $<18.5 \mathrm{~kg} / \mathrm{m}^{2}$ ) and $22 \%$ ( $n$ 13) were overweight (BMI $>25 \mathrm{~kg} / \mathrm{m}^{2}$ ). Infants' age, weight, weight-for-length, length-for-age and weight gain on the 14 th day were similar in both groups.

\section{Breast milk and non-milk intake}

The overall breast milk intake ( $n$ 59) was 870 (SD 215) g/d. It was significantly higher for infants in the Ex group $(P<0 \cdot 01)$. Inversely, non-milk intake was significantly higher for infants in the Part group $(P<0 \cdot 001$; Table 2$)$. Multiple linear regression showed that breast milk intake was positively associated with the infant's weight $(\beta=0.548, P<0.001)$ and negatively associated with non-milk intakes $(\beta=-0.485, P<0.001)$ and breast milk fat content $(\beta=-0.262, P<0.05)$.

\section{Energy intake from breast milk}

The means for creamatocrit and fat content were 4.5 (SD 1.5 ) \% and 31 (SD 9) g/l, respectively, and were comparable in both groups $(P>0 \cdot 05)$. Breast milk energy content was not different between the groups $(P>0.05)$ and the overall mean was 2661 (sD 351) kJ/1 (636 (sD 84) kcal/l) (Table 3). Energy intake from breast milk (derived from the energy content of breast milk and breast milk intake) was significantly higher in the Ex group than in the Part group $(P<0 \cdot 01)$. When corrected for the infant's body weight, the difference became more significant $(P<0 \cdot 001)$. There was no difference between the energy intake of girls and boys within the same group (Table 4).

\begin{tabular}{|c|c|c|c|c|}
\hline & \multicolumn{2}{|c|}{$\begin{array}{c}\text { Ex group } \\
(n 15)\end{array}$} & \multicolumn{2}{|c|}{$\begin{array}{l}\text { Part group } \\
(n 44)\end{array}$} \\
\hline & Mean & SD & Mean & SD \\
\hline \multicolumn{5}{|l|}{ Breast milk intake } \\
\hline $\mathrm{g} / \mathrm{d}$ & 993 & 135 & $828^{\star *}$ & 222 \\
\hline litres $/ d$ & 1.02 & 0.14 & $0.85^{\star *}$ & 0.23 \\
\hline Non-milk intake $(\mathrm{g} / \mathrm{d})$ & 46 & 49 & $250^{\star \star \star}$ & 124 \\
\hline
\end{tabular}

Table 2. Infants' breast milk and non-milk intakes in the two groups

(Mean values and standard deviations) 
Table 3. Breast milk creamatocrit, fat and energy content (Mean values and standard deviations)

\begin{tabular}{lccccc}
\hline & \multicolumn{2}{c}{$\begin{array}{c}\text { Ex group* } \\
(n 15)\end{array}$} & & \multicolumn{2}{c}{$\begin{array}{c}\text { Part group } \\
(n \text { }\end{array}$} \\
\cline { 2 - 3 } \cline { 6 - 7 } & Mean & SD & & Mean & SD \\
\hline Creamatocrit $(\%)$ & 4.24 & 1.12 & & 4.61 & 1.63 \\
Milk fat $(\mathrm{g} / \mathrm{d})$ & 29.07 & 6.65 & & 31.26 & 9.65 \\
Energy content $(\mathrm{kJ} / \mathrm{l})$ & 2598 & 259 & & 2690 & 380
\end{tabular}

Ex group, exclusively breast-fed infants; Part group, partially breast-fed infants.

* There were no significant differences between the groups for each variable $(P>0.05)$.

\section{Discussion}

In the present study, a standard method to measure breast milk intake, the dose-to-the mother ${ }^{2} \mathrm{H}_{2} \mathrm{O}$ turnover method, was used. It is more accurate than test weighing. It does not interfere with the infant's feeding patterns and is easier to achieve in the field ${ }^{(18,24,25)}$. This technique allows the determination of the infant's non-milk intake, the mother's body composition and the infant's mean breast milk intake over a $14 \mathrm{~d}$ period $^{(3,5)}$. Infants were classified by the feeding pattern on the basis of their actual non-milk intake according to Da Costa et al. ${ }^{(4)}$. A non-milk intake cut-off of $100 \mathrm{~g} / \mathrm{d}$ was used to differentiate between the Ex and Part groups. The present results show that the infant's feeding patterns have more consequences on breast milk intake. Indeed, the infants' breast milk intake in the Ex group was significantly higher than that of infants in the Part group. The WHO estimations of breast milk intake for developing countries are $804 \mathrm{~g} / \mathrm{d}$ for exclusively breast-fed infants and $611 \mathrm{~g} / \mathrm{d}$ for partially breast-fed infants ${ }^{(7)}$. These values appear to be significantly lower than those obtained in the present study. In fact, the WHO values were based on a compilation of data generally obtained by test weighing. Breast milk intakes measured by the dose-to-the-mother ${ }^{2} \mathrm{H}_{2} \mathrm{O}$ turnover method are generally higher than the WHO values ${ }^{(4)}$. The overall mean milk intakes in the present study are comparable with published values using the same technique on 6-month-old breast-feeding infants in Mexico $(869 \mathrm{~g} / \mathrm{d})^{(11)}$, Chile $(863 \mathrm{~g} / \mathrm{d})^{(12)}$, Malawi $(910 \mathrm{~g} / \mathrm{d})^{(13)}$ and Iceland $(901 \mathrm{~g} / \mathrm{d})^{(14)}$. These results indicate that exclusively breast-fed infants consume a sufficient amount of breast milk. However the cut-off proposed by Da Costa et al. ${ }^{(4)}$ remains arbitrary and more studies are needed to investigate the effect of non-milk intake on breast milk intake.

As defined by the WHO, energy requirements for 6-monthold infants are $325 \mathrm{~kJ} / \mathrm{kg}$ body weight per d $(78 \mathrm{kcal} / \mathrm{kg}$ body weight per d) for boys and $330 \mathrm{~kJ} / \mathrm{kg}$ body weight per $\mathrm{d}$ (79 kcal/kg body weight per d) for girls ${ }^{(26,27)}$. When applied to the present study, it would equate to $2328 \mathrm{~kJ} / \mathrm{d}(556 \mathrm{kcal} / \mathrm{d})$ for the average Ex group infants and to $2443 \mathrm{~kJ} / \mathrm{d}(583 \mathrm{kcal} / \mathrm{d})$ for the average Part group infants.

The energy content of breast milk was estimated in the present study by creamatocrit, an accurate technique, which was validated on breast milk samples in different conditions $^{(19,23,28-32)}$. Yet, since breast milk fat content varies widely from one breast to another but also according to the collection time, to test properly the nutritional adequacy of a mother's milk, a representative ( $24 \mathrm{~h}$ collection or mid-morning and mid-afternoon collection or total breast expression) sample, which has been well mixed, is needed ${ }^{(28,33,34)}$. Given all these factors and the difficulty of sampling $24 \mathrm{~h}$ milk among our subjects, we chose to collect full milk samples, which consist of a total expression of a breast that was not suckled for at least $2 \mathrm{~h}$. The fat content values that we found are similar to published data on Gambian $24 \mathrm{~h}$ breast milk samples $(39 \mathrm{~g} / \mathrm{l})^{(29)}$ and Senegalese mid-morning and mid-afternoon well-mixed samples $\left(31\right.$ (SD 10) g/l) ${ }^{(35)}$. Breast milk energy content did not differ between the groups and was in the range of the WHO published values for developing countries ${ }^{(33)}$. Indeed, according to the WHO, energy content varies between $2516 \mathrm{~kJ} / 1$ (601 kcal/1) and $3245 \mathrm{~kJ} / 1(775 \mathrm{kcal} / \mathrm{l})$ with a mean of $2717 \mathrm{~kJ} / 1(649 \mathrm{kcal} / \mathrm{l})^{(7)}$.

Expressed as $\mathrm{kJ} / \mathrm{d}$ or $\mathrm{kJ} / \mathrm{kg}$ body weight per $\mathrm{d}$, energy intake from breast milk in the Ex group infants was significantly higher than that in the Part group infants. When their energy intakes were compared with their requirements, boys and girls in the Ex group met their energy needs by breast milk alone, whereas energy intake from breast milk was low for infants in the Part group. Reilly et al. ${ }^{(9)}$ have proposed that the metabolisable energy content of breast milk at the age of 6 months is $260 \cdot 0 \mathrm{~kJ} / 100 \mathrm{~g}(62 \cdot 1 \mathrm{kcal} / 100 \mathrm{~g})$. Using these estimates, the infants' energy intake from breast milk would be $2582 \mathrm{~kJ} / \mathrm{d}(616 \mathrm{kcal} / \mathrm{d})$ in the Ex group

Table 4. Infants' daily energy intake from breast milk*

(Mean values and standard deviations)

\begin{tabular}{|c|c|c|c|c|c|c|c|c|c|c|c|c|}
\hline & \multicolumn{6}{|c|}{ Ex group (n 15) } & \multicolumn{6}{|c|}{ Part group (n 40) } \\
\hline & \multicolumn{2}{|c|}{ Boys } & \multicolumn{2}{|c|}{ Girls } & \multicolumn{2}{|c|}{ Overall } & \multicolumn{2}{|c|}{ Boys } & \multicolumn{2}{|c|}{ Girls } & \multicolumn{2}{|c|}{ Overall } \\
\hline & Mean & SD & Mean & SD & Mean & SD & Mean & SD & Mean & SD & Mean & SD \\
\hline \multicolumn{13}{|c|}{ Energy intake from breast milk } \\
\hline $\mathrm{kJ} / \mathrm{d}$ & 2690 & 548 & 2531 & 410 & $2586^{a}$ & 448 & 2263 & 489 & 2079 & 585 & $2150^{b}$ & 552 \\
\hline $\mathrm{kJ} / \mathrm{kg}$ per d† & 372 & 75 & 360 & 42 & $364^{c}$ & 50 & 297 & 54 & 284 & 71 & $289^{d}$ & 66 \\
\hline
\end{tabular}

Ex group, exclusively breast-fed infants; Part group, partially breast-fed infants.

a,b,c,d Mean values within a row with unlike superscript letters were significantly different: $\mathrm{a}>\mathrm{b}(P<0.01), \mathrm{c}>\mathrm{d}(P<0.001)$

* There were no difference between boys and girls in the same group.

† Obtained by dividing the infants' daily energy intake by their weight. 
and $2153 \mathrm{~kJ} / \mathrm{d}(514 \mathrm{kcal} / \mathrm{d})$ in the Part group, which are not different from the values obtained by creamatocrit. These results are not very different from those found by Wells et $a l .^{(14)}$ in 6-month-old exclusively and partially breast-fed infants in Iceland. Infants had good nutritional status in both groups and exhibited normal growth. These results suggest that partially breast-fed infants (Part group) also meet their energy requirements by breast milk and non-milk intakes that are high for these infants.

Maternal nutritional status did not affect breast milk intake. In fact, no association was found between breast milk intake and the mother's BMI and body composition (fat-free mass and fat mass). However, the present study is consistent with published results showing that infants' characteristics affect their milk intake. A positive association was found between breast milk intake and the infant's weight. Breast milk intake was negatively associated with non-milk intake. In the present study, $48 \%$ of breast milk intake variation can be explained by the infant's intake of water and other foods. This result corroborates previous studies ${ }^{(4,36,37)}$ about the effect of complementary feeding on breast milk intake. The present findings are consistent with the WHO's conclusion indicating that early introduction of other liquid and/or foods in infant feeding should be avoided in order to optimise the intake of breast milk, which is the most suitable food for the infant ${ }^{(38)}$. Furthermore, recent cohort studies have shown that the late introduction of complementary foods (at 6 months) would protect the infant against adulthood obesity ${ }^{(39,40)}$.

The present study demonstrates that 6-month-old Senegalese exclusively breast-fed infants consume sufficient amounts of breast milk. They receive an adequate amount of energy from breast milk to meet their energy requirements. Although partially breast-fed infants cover their energy needs as shown from their growth data, early introduction of complementary foods by this age reduces the consumption of breast milk. Since breast milk is the most complete food for infants, and uncontrolled complementary foods are potential risks of infections, advocacy of exclusive breastfeeding should be strengthened in countries where safe water intake is an issue.

\section{Acknowledgements}

The present study was supported by the International Atomic Energy Agency (IAEA), TC project SEN60/16, and the University of Dakar, Senegal. We would like to thank the mothers and infants who participated in the study, the health centre's staff, the nurses, the fieldworkers and the laboratory of Nutrition UCAD staff (students and technicians) for their support and contributions. We also thank Dr Les Bluck for the initial reviews and feedback on the manuscript. S. W., A. A.-D. and K. M. K. designed the study and implemented the protocol. A. A.-D. and K. M. K. completed the field, clinical data collection and analyses. A. D., N. I.-D. and A. T. G. provided the training. S. W., K. M. K. and A. A.-D. wrote the manuscript. All authors reviewed and approved the final manuscript. The authors have no conflicts of interest to declare.

\section{References}

1. World Health Organization (2002) The World Health Report: Reducing Risks, Promoting Healthy Life. Geneva: WHO.

2. Moore S, Prentice A \& Coward WA (2007) Use of stable isotope to validate infant feeding practices reported by Bangladeshi women. Am J Clin Nutr 85, 1075-1082.

3. Haisma H, Coward AW, Albernaz E, et al. (2003) Breast-milk and energy intake in exclusively, predominantly, and partially breast-fed infants. Eur J Clin Nutr 57, 1633-1642.

4. Da Costa THM, Haisma H, Wells JCK, et al. (2010) How much human milk do infants consume? Data from 12 countries using a standardized stable isotope methodology. J Nutr 140, 2227-2232.

5. Fewtrell MS, Morgan JB, Duggan C, et al. (2007) Optimal duration of exclusive breastfeeding: what is the evidence that support current recommendations? Am J Clin Nutr $\mathbf{8 5}$, Suppl. 2, S635-S638.

6. World Health Organization (2002) The Optimal Duration of Exclusive Breastfeeding. A Systematic Review. Geneva: WHO.

7. World Health Organization (2002) Nutrient Adequacy of Exclusive Breastfeeding for the Term Infant During the First Six Months of Life. Geneva: WHO.

8. World Health Organization (2003) Global Strategy for Infant and Young Child Feeding. Geneva: WHO.

9. Reilly JJ, Ashworth S \& Wells JCK (2005) Metabolisable energy consumption in the exclusively breast-fed infant aged 3-6 months from the developed world: a systematic review. Br J Nutr 94, 56-63.

10. Reilly JJ \& Wells JCK (2005) Duration of exclusive breastfeeding: introduction of complementary feeding may be necessary before 6 months of age. Br J Nutr 94, 869-872.

11. Butte NF, Villalpando S, Wong WW, et al. (1992) Human milk intake and growth faltering of rural Mesoamerindian infants. Am J Clin Nutr 55, 1109-1116.

12. Alvear J, Salazar G, Berlanga R, et al. (2004) Breastfeeding and growth in a group of selected 0 to 24 months infants. In International Atomic Agency (IAEA). Coordinated Research Project on Isotopic Evaluation in Infant Growth Monitoring: A Collaboration with WHO (Partly RCA). Vienna: INIS.

13. Galpin L, Thakwalakwa C, Phuka J, et al. (2007) Breastmilk intake is not reduced more by the introduction of energy dense complementary food than typical infant porridge. J Nutr 137, 1828-1833.

14. Wells JCK, Jonsdottir OH, Hibberd PL, et al. (2012) Randomized controlled trial of 4 compared with 6 mo of exclusive breastfeeding in Iceland: differences in breast-milk intake by stable-isotope probe. Am J Clin Nutr 96, 73-79.

15. Coward AW, Cole TJ, Sawyer MB, et al. (1982) Breast-milk intake measurement in mixed-fed infants by administration of deuterium-oxide to their mothers. Hum Nutr Clin Nutr 36C, 141-148.

16. Cissé AS, Bluck L, Diaham B, et al. (2002) Use of Fourier transformed infrared spectrophotometer (FTIR) for determination of breast-milk output by the deuterium dilution method among Senegalese women. Food Nutr Bull 23, Suppl. 3, S138-S1341.

17. Albernaz E, Victoria CG, Haisma H, et al. (2003) Lactation counselling increases breastfeeding duration but not breast-milk intake as measured by isotopic methods. J Nutr 133, 205-210.

18. International Atomic Energy Agency (2010) Human Health Series No. 7: Stable Isotope Technique to Assess Intake of Human Milk in Breastfed Infants. Vienna: IAEA. 
19. Lucas A, Gibbs JAH, Lyster RLJ, et al. (1978) Creamatocrit: simple clinical technique for estimating fat concentration and energy value of human milk. Br Med Ji i, 1010-1020.

20. Coward AW, Whitehead RG, Sawyer MB, et al. (1979) New method for measuring milk intakes in breast-fed babies. Lancet 314, 13-14.

21. Racette SB, Schoeller DA, Luke AH, et al. (1994) Relative dilution spaces of ${ }^{2} \mathrm{H}$ - and ${ }^{18} \mathrm{O}$-labeled water in humans. Am J Physiol 267, E585-E590.

22. International Atomic Energy Agency (1990) The doubly labelled water method for measuring energy expenditure. In Technical Recommendations for Use in Humans. A Consensus Report by IDECG Working Group [AM Prentice, editor]. Vienna: NAHRES-4, International Atomic Energy Agency.

23. Meier PP, Engstrom JL, Zuleger JL, et al. (2006) Accuracy of a user-friendly centrifuge for measuring creamatocrits on mother's milk in the clinical setting. Breastfeed Med 1, 79-87.

24. Infante C, Lara W \& Vio F (1985) Isotope dilution measurement of breast-milk production in Chilean urban mothers. Hum Nutr Clin Nutr 39C, 379-386.

25. Savenije OEM \& Wells JCK (2006) Accuracy and precision of test weighing to assess milk intake in newborn infants. Arch Dis Child Fetal Neonatal 91, F330-F332.

26. World Health Organization (2004) Human Energy Requirements. Report of a Joint FAO/WHO/UNU Expert Consultation, p. 96. Rome: FAO.

27. Butte NF (2005) Energy requirements of infants. Public Health Nutr 8, 953-967.

28. Lemons JA, Shreiner LR \& Gresham EL (1980) Simple method for determining the caloric and fat content of human milk. Pediatrics 66, 626-628.

29. Prentice A, Prentice AM \& Whitehead RG (1981) Breast-milk fat concentrations of rural African women. 2. Long-term variations within a community. Br J Nutr 45, 495-503.

30. Wang CD, Chu PS, Mellen BG, et al. (1999) Creamatocrit and the nutrient composition of human milk. J Perinatol 19, 343-346.

31. Meier PP, Engstrom JL, Murtaugh MA, et al. (2002) Mother's milk feedings in the neonatal intensive care unit: accuracy of the creamatocrit technique. J Perinatol 22, 646-649.
32. Mandel D, Lubetzky R, Dollberg S, et al. (2005) Fat and energy contents of expressed human breast milk in prolonged lactation. Pediatrics 116, e432-e435.

33. Organisation Mondiale de la Santé (1987) Quantité et qualité du lait maternel: rapport sur une étude collective consacrée à l'allaitement au sein (Quantity and Quality of Breast Milk: Report of a Study Group Devoted to Breastfeeding). Genève: OMS

34. Rocquelin G, Tapsoba S, Mbemba F, et al. (1998) Lipid content and essential fatty acid (EFA) composition of mature Congolese breast milk are influenced by mother's nutritional status: impact on infant's EFA supply. Eur J Clin Nutr 52, $164-171$

35. Cissé AS (2004) Intérêt de l'utilisation des isotopes stables dans la mesure de la production lactée et de la composition corporelle: effet de la supplémentation alimentaire durant la grossesse et l'allaitement sur la quantité, la qualité et les apports en nutriments du lait maternel et sur l'état nutritionnel des nourrissons (Interest in the use of stable isotopes in measuring milk production and body composition: the effect of dietary supplementation during pregnancy and lactation on the quantity, quality and nutrient intake of breast milk and the nutritional status of infants). Thèse de Doctorat de $3^{\mathrm{e}}$ cycle, Université Cheikh Anta Diop de Dakar.

36. Heinig MJ, Nommsen LA, Peerson JM, et al. (1993) Intake and growth of breast-fed and formula fed infants in relation to the timing of introduction of complementary foods. The DARLING study. Acta Paediatr 82, 999-1006.

37. Islam MM, Peerson JM, Ahmed T, et al. (2006) Effects of varied energy density of complementary foods on breastmilk intakes and total energy consumption by healthy breastfed Bangladeshi children. Am J Clin Nutr 83, 851-858.

38. World Health Organization (1998) Complementary Feeding of Young Children in Developing Countries: A Review of Current Scientific Knowledge. Geneva: WHO.

39. Nommsen-Rivers LA \& Dewey KG (2009) Growth of breastfed infants. Breastfeed Med 4, Suppl. 1, S45-S49.

40. Shack-Nielsen L, Sorensen TIA, Mortensen EL, et al. (2010) Late introduction of complementary feeding, rather than duration of breastfeeding, may protect against adult overweight. Am J Clin Nutr 91, 619-627. 